\title{
Prevalence of Malocclusion Traits in Saudi Males Seeking Orthodontic Treatment in Najran in Saudi Arabia
}

\author{
Ahmed M Alassiry
}

\begin{abstract}
Aim: To study the prevalence of different malocclusion traits in Najran in Saudi adolescents and adults seeking orthodontic treatment in Najran in Saudi Arabia.

Materials and methods: Two hundred and fifty male patients in the age group of 12-35 years who visited faculty of dentistry in Najran University for orthodontic treatment were examined and were divided into two age groups, adolescents and adults. The patients were examined and classified into Class I, Class II, and Class III malocclusions. They were also examined for overjet, overbite, open bite, crossbite, scissor's bite, crowding, and spacing.

Results: The prevalence of Angle's malocclusion Classes I, II, and III was 52.8\%, 31.6\%, and 15.6\%, respectively. The most common anomaly was moderate overbite followed by lateral open bite. Posterior crossbite was found to be more prevalent than anterior crossbite.

Conclusion: Angle's Class I malocclusion was most prevalent type, followed by Class II, and then Class III.

Clinical significance: The findings of this study can be used to formulate an appropriate preventive and orthodontic treatment measures pertaining to the population of adolescent and adult Saudi males.

Keywords: Adolescents, Adults, Malocclusion, Prevalence, Saudi males.

The Journal of Contemporary Dental Practice (2020): 10.5005/jp-journals-10024-2859
\end{abstract}

\section{INTRODUCTION}

Malocclusion refers to any type of irregular contact between the upper and lower teeth. It can manifest as an overbite, open bite, under bite, or crossbite. Malocclusion can be defined as an occlusion in which there is a malrelationship between the arches in any of the planes or in which there are anomalies in tooth position, number, form, and developmental position of teeth beyond normal limits. ${ }^{1}$

Facial appearance has a long lasting implication on an individual. Malocclusion is a highly prevalent dental deformity, which was shown to have several consequences: physical, economic, social, and psychological impacts. ${ }^{2}$ An unacceptable dental appearance has often been associated with a negative effect on self-image, career advancement, and peer-group acceptance. The adolescents often get subjected to teasing and intimidation which produces a feeling of inferiority leading to an incompetent social and intellectual well-being.

Angle's classification of malocclusion in 1890s was an important step in the development of orthodontics because it not only subdivided major types of malocclusion but also included the first clear and simple definition of normal occlusion in the natural dentition. ${ }^{3}$

The prevalence of malocclusion has increased in the past few years and is one of the most common dental problems today. It varies widely and these variations are difficult to explain. It may depend on differences in recording approaches, ethnic origin, social class, or age of the examined subjects. ${ }^{4}$ However, diagnostic criteria are the key factors determining the prevalence of malocclusion. ${ }^{5}$

Malocclusion also has a large impact on both individuals and society in terms of discomfort, quality of life, and social and functional limitations $s^{6,7}$

The aim of this study was to determine the distribution of malocclusion traits based on Angle's classification in adolescent
Department of Preventive Dental Sciences, Faculty of Dentistry, Najran University, Najran, Kingdom of Saudi Arabia

Corresponding Author: Ahmed M Alassiry, Department of Preventive Dental Sciences, Faculty of Dentistry, Najran University, Najran, Kingdom of Saudi Arabia, Phone: +966504135127, e-mail: ahmedassiry@hotmail.com

How to cite this article: Alassiry AM. Prevalence of Malocclusion Traits in Saudi Males Seeking Orthodontic Treatment in Najran in Saudi Arabia. J Contemp Dent Pract 2020;21(6):686-690.

Source of support: Nil

Conflict of interest: None

and adult male patients seeking orthodontic treatment in faculty of dentistry in Najran, Saudi Arabia

\section{Materials and Methods}

The sample consisted of 250 Saudi male patients in the age group of 12-35 years who visited faculty of Dentistry in Najran University for orthodontic treatment. The selected sample was divided into two age groups: Adolescents (patients belonging to the age group of 12-17 years) and adults (patients belonging to the age group of 18-35 years). Accordingly, the sample consisted of 151 adults and 99 adolescents. The objectives and benefits of the study were clearly mentioned to the patients, and a written form of informed consent was taken. For patients below the age of 18 years, consent was obtained from their parents or guardians.

The patients included in this study had not undergone previous orthodontic treatment. The assessment was performed independently by a single investigator so as to eliminate any interexaminer variations. The patients were examined and classified into Class I, Class II, and Class III malocclusions according to Angle's

(c) The Author(s). 2020 Open Access This article is distributed under the terms of the Creative Commons Attribution 4.0 International License (https://creativecommons. org/licenses/by-nc/4.0/), which permits unrestricted use, distribution, and non-commercial reproduction in any medium, provided you give appropriate credit to the original author(s) and the source, provide a link to the Creative Commons license, and indicate if changes were made. The Creative Commons Public Domain Dedication waiver (http://creativecommons.org/publicdomain/zero/1.0/) applies to the data made available in this article, unless otherwise stated. 
classification. They were also examined for overjet, overbite, open bite, crossbite, scissor's bite, crowding, and spacing according to the method used by Bjork et al. ${ }^{8}$

\section{Sagittal Dimension}

Sagittal relationship were classified as Class I, Class II, and Class III according to Angle's classification. ${ }^{9}$

Overjet is the horizontal overlap between maxillary incisors and mandibular incisors. Overjet between $4 \mathrm{~mm}$ and $6 \mathrm{~mm}$ was considered moderate and more than $6 \mathrm{~mm}$ was considered severe. An edge-to-edge overbite was considered when upper and lower teeth meet in a straight line with zero overjet. Anterior crossbite was considered when maxillary incisors were lingual in position in relation to the mandibular incisors.

\section{Vertical Dimension}

Overbite is the vertical overlap between maxillary and mandibular incisors. Overbite between 4 and $6 \mathrm{~mm}$ was considered moderate and greater than $6 \mathrm{~mm}$ was considered severe.

An open bite (anterior) was registered if the space between upper and lower incisors was $1 \mathrm{~mm}$ or more than $1 \mathrm{~mm}$ and lateral open bite was considered if at least two pairs of antagonist teeth fail to meet unilaterally or bilaterally.

\section{Transverse Dimension}

A posterior crossbite was registered when the buccal cusps of the maxillary premolars and/or molars occluded lingual to the buccal cusps of the mandibular antagonists (at least one pair of teeth, uni-, or bilateral).

A scissor bite was recorded when any of the maxillary premolars or molars occluded with the buccal surface of the mandibular antagonist teeth (uni- or bilateral).

\section{Alignment Anomalies}

Space in upper and lower arches exceeding $2 \mathrm{~mm}$ was considered spacing. ${ }^{10-13}$

Crowding was recorded in upper arch and lower arch. Crowding was considered if there was $2 \mathrm{~mm}$ or more in each dental arch. Scissor bite was recorded when palatal surface of maxillary posterior teeth occluded buccal to the buccal cusp of lower posterior teeth.

Data analysis was performed using SPSS 16.0 and the distribution for occurrence of different malocclusion traits was determined in female adolescent and adult patients. Pearson's Chi-square test was done to determine $p$ value.

\section{Results}

This study consisted of 250 male patients. The age range in this study was $12-35$ years. The study sample was divided into two age groups: age group of 12-17 years (adolescents) and age group of $18-35$ (adults). Adults constituted $60.4 \%$ of the sample, while adolescents represented the remaining $39.6 \%$ (Fig. 1).

Table 1 shows that Angle Class I classification was found to be most prevalent (52.8\%) followed by Class II (31.6\%) and Class III (15.6\%). The total number with Angle's Class I malocclusion $(N=250)$, was distributed as $53.2 \%$ adults and $47 \%$ adolescents. This was not the case for Class II malocclusion where only $75.9 \%$ of adults and $24.1 \%$ adolescents showed it. On the contrary, $53.8 \%$ and $46.2 \%$ of the total number of Class III were adults and adolescents, respectively.

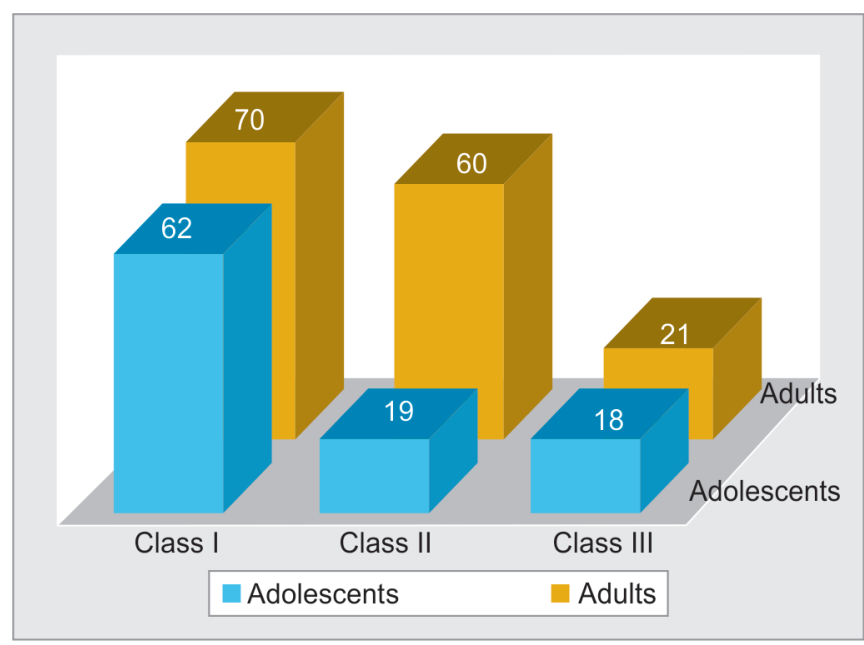

Fig. 1: Percentage and distribution of Angle's classification in adolescents and adults

Among the adolescents, it was observed that Class I was the most prevalent followed by Class II and then Class III. The same pattern was observed in adults with Class I being the most prevalent followed by Class II and then Class III.

The percentage distribution of different malocclusion traits in adolescents and adults has been recorded in Table 2 .

With regard to overjet, $42.8 \%$ and $33.3 \%$ of the adolescents exhibited moderate and severe overjet while $57.2 \%$ and $66.7 \%$ of the adults showed moderate and severe overjet, respectively.

Anterior crossbite was observed in only $53.3 \%$ of adults and $46.6 \%$ of adolescents. As for posterior crossbite, $69.4 \%$ of the adults and $30.6 \%$ of the adolescents showed unilateral crossbite. A vast majority of the adults $69.2 \%$ showed bilateral crossbite while only $30.8 \%$ adolescents showed it. Unilateral scissor bite was observed in $1.51 \%$ of the adults and $2.27 \%$ of the adolescents. However bilateral scissor bite was not observed both in adolescents and adults.

Table 2 shows that higher percentage of adults showed anterior crossbite and posterior crossbite (uni- and bilateral). Unilateral crossbite showed a higher percentage than bilateral type. In addition, unilateral scissor bite was more frequently observed in as compared to bilateral scissor bite, which was absent in both adolescents and adults.

Overbite: $\mathbf{5 7 . 1 \%}$ adults and $\mathbf{4 2 . 9 \%}$ adolescents exhibited edgeto-edge overbite. Moderate overbite was observed in $100 \%$ of the adolescents. In contrast, none of the adults showed moderate overbite. This was in contrast to severe overbite where a majority of the adults, $69.2 \%$ manifested severe overbite while only $30.8 \%$ of the adolescents exhibited it.

Anterior open bite was present in $52.4 \%$ of the adults and $47.6 \%$ of the adolescents. However, lateral open bite was more frequent in adolescents and $87.5 \%$ of adolescents showed it, whereas only $12.5 \%$ of the adults showed lateral crossbite.

With regard to crowding and spacing, adolescents showed $38.8 \%$ and $30.8 \%$ crowding in maxillary and mandibular arches, respectively. As for the adults, crowding was present in $61.2 \%$ and $69.2 \%$ of the maxillary and mandibular arches, respectively. In adults, higher percentage of mandibular spacing was seen (64\%) than maxillary spacing (57.9\%). This was reversed in adolescents where maxillary spacing was more prevalent (42.1\%) than mandibular (36.0\%). 
Table 1: Percentage and distribution of Angle's classification in adolescents and adults

\begin{tabular}{|c|c|c|c|c|c|c|}
\hline \multirow[b]{2}{*}{ Angle's classification } & \multicolumn{2}{|c|}{ Total (250) } & \multicolumn{2}{|c|}{ Adolescents } & \multicolumn{2}{|c|}{ Adults } \\
\hline & Number & (\%) & Number & (\%) & Number & $(\%)$ \\
\hline Class I & 132 & 52.8 & 62 & 47.0 & 70 & 53.2 \\
\hline Class II & 79 & 31.6 & 19 & 24.1 & 60 & 75.9 \\
\hline Class III & 39 & 15.6 & 18 & 46.2 & 21 & 53.8 \\
\hline
\end{tabular}

Table 2: Percentage and distribution of malocclusion traits in both adolescents and adults

\begin{tabular}{|c|c|c|c|c|c|}
\hline \multirow[b]{2}{*}{ Malocclusion } & \multicolumn{2}{|c|}{ Adolescents } & \multicolumn{2}{|c|}{ Adults } & \multirow{2}{*}{$\begin{array}{r}\text { Total } \\
\text { Number }\end{array}$} \\
\hline & Number & (\%) & Number & (\%) & \\
\hline \multicolumn{6}{|l|}{ Overjet } \\
\hline Normal & 29 & 35.8 & 52 & 64.2 & 81 \\
\hline Moderate 4-6 mm & 62 & 42.8 & 83 & 57.2 & 145 \\
\hline Severe $>6 \mathrm{~mm}$ & 8 & 33.3 & 16 & 66.7 & 24 \\
\hline \multicolumn{6}{|l|}{ Anterior crossbite } \\
\hline Normal & 85 & 38.6 & 135 & 61.4 & 220 \\
\hline Anterior crossbite & 14 & 46.7 & 16 & 53.3 & 30 \\
\hline \multicolumn{6}{|l|}{ Posterior crossbite } \\
\hline Normal & 84 & 41.8 & 117 & 58.2 & 201 \\
\hline Unilateral & 11 & 30.6 & 25 & 69.4 & 36 \\
\hline Bilateral & 4 & 30.8 & 9 & 69.2 & 13 \\
\hline \multicolumn{6}{|l|}{ Scissors bite } \\
\hline Unilateral & 3 & 2.27 & 2 & 1.51 & 5 \\
\hline Bilateral & - & - & - & - & - \\
\hline \multicolumn{6}{|l|}{ Overbite } \\
\hline Normal & 25 & 16.6 & 126 & 83.4 & 151 \\
\hline Edge-to-edge & 12 & 42.9 & 16 & 57.1 & 28 \\
\hline Moderate 4-6 mm & 58 & 100.0 & 0 & 0 & 58 \\
\hline Severe $>6 \mathrm{~mm}$ & 4 & 30.8 & 9 & 69.2 & 13 \\
\hline \multicolumn{6}{|l|}{ Open bite } \\
\hline Normal & 82 & 37.1 & 139 & 62.9 & 221 \\
\hline Anterior & 10 & 47.6 & 11 & 52.4 & 21 \\
\hline Lateral & 7 & 87.5 & 1 & 12.5 & 8 \\
\hline \multicolumn{6}{|l|}{ Crowding } \\
\hline Normal & 40 & 52.6 & 36 & 47.4 & 76 \\
\hline Maxillary & 26 & 38.8 & 41 & 61.2 & 67 \\
\hline Mandibular & 33 & 30.8 & 74 & 69.2 & 107 \\
\hline \multicolumn{6}{|l|}{ Spacing } \\
\hline Normal & 66 & 39.3 & 102 & 60.7 & 168 \\
\hline Maxillary & 24 & 42.1 & 33 & 57.9 & 57 \\
\hline Mandibular & 9 & 36.0 & 16 & 64.0 & 25 \\
\hline
\end{tabular}

\section{Discussion}

The prevalence of malocclusion varies widely depending on the population, race, and age, and it is very important in determining and planning orthodontic treatment. The data collected in this study will help in understanding the distribution of the traits of malocclusion in the Saudi male population (Najran area) and establish a proper preventive and orthodontic treatment programs.

The sample used for this study consisted of adolescents and adults belonging to the age group of 12 to 35 years as these are the most frequent age group for those seeking orthodontic treatment. This is in similar to the studies by al-Emran et al. ${ }^{14}$ and Nashashibi et al. ${ }^{15}$
Angle's classification has been used in this study as it is a universally accepted system that is reliable and repeatable and that minimizes examiner subjectivity. ${ }^{16}$ Distribution of different types of malocclusion may show great variability even in a population of same origin. ${ }^{17}$

This study revealed that Angle Class I malocclusion was considered the most prevalent type of malocclusion with $52.8 \%$ followed by Class II with $31.6 \%$ and Class III with $15.6 \%$ among the orthodontic patients examined. This was in agreement with the study conducted by Meer et al., ${ }^{18}$ al Emran et al., ${ }^{14}$ and Al-Balkhi and Zahrani ${ }^{19}$ who reported that the most common type of malocclusion was Class I, followed by Class II, and then Class III 
in the Saudi patients. Gudipaneni et al. ${ }^{20}$ in a study conducted on Northern border region of Saudi Arabia also found that Angle Class I was the most prevalent malocclusion with $52.8 \%$ followed by Angle's Class II (31.8\%) and Angle's Class III (15.4\%). The results of this study are also in accordance with the research conducted by AlQarni et al. ${ }^{21}$ in Asser region of Saudi Arabia in which Class I malocclusion (75\%) was found to be most common, followed by Angle's Class II malocclusion (14\%) and Angle's Class III malocclusion (11\%). Another study conducted in the population of Dammam city by Al-Shahrani et al. ${ }^{22}$ found that the Class I malocclusion was most prevalent (61.6\%), followed by Class II (31.8\%) which is similar to the findings of this study. When compared to other countries, Nigeria ${ }^{23}$ reported $76.5 \%$ and Turkey ${ }^{24}$ reported $74 \%$ cases of Angle's Class I malocclusion in their population. In Pakistan, ${ }^{10}$ Angle's Class II malocclusion (70.5\%) was more prevalent amongst orthodontic patients. In urban Iranian population ${ }^{25}$ and Jordanian school children, ${ }^{26}$ Angle's Class I malocclusion was found to be more prevalent by $41.8 \%$ and $55.3 \%$, respectively. In a recent systematic review conducted by Alhammadi et al., ${ }^{27}$ the highest prevalence of Class I malocclusion was reported in the African population, whereas the Caucasians and Europe population showed the highest prevalence of Class II malocclusion.

The different types of malocclusion anomalies that were observed were overjet, crossbite, overbite, open bite, crowding, and spacing. Similar occlusal anomalies were observed in a study by Hosam Baeshen. ${ }^{28}$

Among the different malocclusion traits which were observed, the most common anomaly was moderate overbite which was found to be $42.8 \%$ in adolescents and $66.7 \%$ in adults followed by lateral open bite which was found to be $87.5 \%$ in adolescents and $12.5 \%$ in adults. Gudipaneni et al. ${ }^{20}$ reported excessive overbite in $23.4 \%$ and reduced overbite in $12.2 \%$ in Northern border region of Saudi Arabia. In the similar study, excessive overjet was found to be $22.2 \%$ and reduced overjet was found to be $11.4 \%$ of population. Albakri et al. ${ }^{29}$ in a study conducted in Riyadh, Saudi Arabia, concluded that deep bite was found in $9.6 \%$ and open bite was present in $4 \%$ of the population. In the same study, the normal overjet was seen in $75.4 \%$, slight increase in overjet was found in $15.2 \%$, and severe increase in overjet was found in $6.6 \%$ of the population.

In this study, posterior crossbite was found to be more prevalent than anterior crossbite. Albakri et al. ${ }^{29}$ reported $4.6 \%$ bilateral crossbite and $1.4 \%$ unilateral crossbite in the population of Riyadh, Saudi Arabia.

With regard to crowding, adolescents showed more crowding in the maxillary arch (38.8\%) compared to mandibular arch (30.8\%). In adults, the findings were opposite to that of adolescents. Mandibular crowding (69.2\%) was more frequently present than maxillary crowding (61.2\%) in adults. This can be attributed to large teeth, small jaw, or a combination of both. Gudipaneni et al. ${ }^{20}$ reported crowding in $47.2 \%$ of patients in Northern border region of Saudi Arabia. AlQarni et al. ${ }^{21}$ reported crowding in $40 \%$ of patients in Asser region of Saudi Arabia. Albakri et al. ${ }^{29}$ found $23.2 \%$ crowding in maxilla and $28 \%$ crowding in mandible in Riyadh, Saudi Arabia.

In this study, in adults, spacing was more prevalent in mandibular arch (64\%) compared to maxillary arch (57.9\%). In the adolescent group, it was observed that the space discrepancies were more common in the maxilla (42.1\%) than in the mandible (36\%). This finding can be associated to the hereditary factors in tooth size-arch length discrepancies. The findings of this study are in accordance with the study conducted by Albakri et al. ${ }^{29}$ who reported maxillary spacing (11.6\%) more frequently than mandibular spacing (8.8\%) in the population of Riyadh, Saudi Arabia. On the contrary, al-Emran et al. ${ }^{14}$ reported higher frequency of spacing in the mandibular arch. This could be due to the differences in age and gender distribution in this study.

The current study achieved its objective by identifying the prevalence of various malocclusion traits in the adolescent and adult male population of Saudi Arabia. Limitations of the study lie in the fact that only male population were included in the study. Moreover, Saudi Arabia due to its ethnically mixed cosmopolitan population has mixed races. Hence, further large-scale studies involving more population are required to provide accurate malocclusion traits of Najran area in the Saudi population.

\section{ConClusion}

In this study, the prevalence of Angle's Class I, Class II, and Class III malocclusions was found to be $52.8 \%, 31.6 \%$, and $15.6 \%$, respectively in the adolescent and adult males in Najran population. The most common anomaly was found to be moderate overbite followed by lateral open bite. Posterior crossbite was found to be more prevalent than anterior crossbite.

The epidemiological data of this study can help in understanding the prevalent traits of malocclusion pertaining to the population of adolescent and adult Saudi males in Najran. to formulate an appropriate preventive and orthodontic treatment measures. The authors recommend the utilization of these data in formulating an appropriate preventive and orthodontic treatment measures for the required population.

\section{References}

1. Houston WJ. Walther's Orthodontic Notes, ch. 6. 4th ed., The Stonebridge Publishers; 2000. pp. 46-50. Available from: http://www. alibris.com/search/books/isbn/9780723606703.

2. Bedi R, Gulati N, McGrath C. A study of satisfaction with dental services among adults in the United Kingdom. Br Dent J 2005;198(7):433-437. DOI: $10.1038 /$ sj.bdj.4812198.

3. McLain JB, Proffitt WR. Oral health status: prevalence of malocclusion. J Dent Educ 1985;49(6):386-397.

4. Thilander B, Pena L, Infante C, et al. Prevalence of malocclusion and orthodontic treatment need in children and adolescents in Bogota, Colombia. an epidemiological study related to different stages of dental development. Eur J Orthod 2001;23(2):153-167. DOI: 10.1093/ ejo/23.2.153.

5. Sidlauskas A, Lopatiene K. The prevalence of malocclusion among 7-15-year-old Lithuanian school children. Medicina (Kaunas) 2009;45(2):147-152. DOI: 10.3390/medicina45020019.

6. Shivakumar KM, Chandu GN, Subba Reddy VV, et al. Prevalence of malocclusion and orthodontic treatment needs among middle and high school children of Davangere city, India by using dental aesthetic index. J Indian Soc Pedod Prev Dent 2009;27(4):211-218. DOI: 10.4103/0970-4388.57655.

7. Proffit WR, Fields HW, Sarver DM. Contemporary Orthodontics. 4th ed., India: Mosby, Health Science imprints of Elsevier; 2008. pp. 3-23.

8. Bjork A, Krebs A, Solow B. A method for epidemiological registration of malocclusion. Acta Odontol Scand 1964;22(1):27-41. DOI: 10.3109/00016356408993963.

9. Angle E. Malocclusion of the teeth. In: Moyers RE. Handbook of Orthodontics. 4th ed., Chicago: Yearbook Med Publ Inc.; 1988. pp. 186-188.

10. Gul-E-Erum, Fida M. Pattern of malocclusion in orthodontic patients: a hospital based study. J Ayub Med Coll Abbottabad 2008;20(1):43-47. 
11. Gelgor IE, Karaman A, Ercan E. Prevalence of malocclusion among adolescents in Central Anatolia. Euro J Dent 2007;1:125-131.

12. Vibhute $A H$, Vibhute NA, Daule R. Prevalence of malocclusion characteristic and chief motivational factors for treatment in orthodontic patients from Maharashtra, India. J Orthodont Res 2013;1(Issue 2):62-65. DOI: 10.4103/2321-3825.116285.

13. Mugonzibwa EA, Eskeli R, Laine-Alava MT, et al. Spacing and crowding among African and Caucasian children. Orthod Craniofac Res 2008;11(2):82-89. DOI: 10.1111/j.1601-6343.2007. 00416.x.

14. al-Emran S, Wisth PJ, Böe OE. Prevalence of malocclusion and need for orthodontic treatment in Saudi Arabia. Community Dent Oral Epidemiol 1990;18(5):253-255. DOI: 10.1111/j.1600-0528.1990. tb00070.x.

15. Nashashibi I, Darwish SK, El Khalifa R. Prevalence of malocclusion and treatment needs in Riyadh (Saudi Arabia). Odontostomatol Trop 1983;6(4):209-214.

16. Silva RG, Kang DS. Prevalence of malocclusion among Latino adolescents. Am J Orthod Dentofacial Orthop 2001;119(3):313-315. DOI: $10.1067 / \bmod .2001 .110985$.

17. Sayin MO, Türkkahraman $\mathrm{H}$. Malocclusion and crowding in an orthodontically referred Turkish population. Angle Orthodont 2004;74((No. 5):635-639.

18. Meer Z, Sadatullah S, Wahab MA, et al. Prevalence of malocclusion and its common traits in Saudi males of Aseer region. J Dent Res Rev 2016;3(3):99-102. DOI: 10.4103/2348-2915.194834.

19. Al-Balkhi KM, Zahrani AA. The pattern of malocclusions in Saudi Arabian patients attending for orthodontic treatment at college of King Saud University, Riyadh. Saudi Dent J 1994;6(3):138-144.

20. Gudipaneni RK, Aldahmeshi RF, Patil SR, et al. The prevalence of malocclusion and the need for orthodontic treatment among adolescents in the northern border region of Saudi Arabia: an epidemiological study. BMC Oral Health 2018;18(1):16. DOI: 10.1186/ s12903-018-0476-8.

21. AlQarni MA, Banihuwaiz AH, Alshehri FD, et al. Evaluate the malocclusion in subjects reporting for orthodontic treatment among Saudi population in Asser Region. J Int Oral Health: JIOH 2014;6(4):42.

22. Al-Shahrani N, Al-Amri A, Hegazi F, et al. The prevalence of premature loss of primary teeth and its impact on malocclusion in the eastern province of Saudi Arabia. Acta Odontol Scand 2015;73(7):544-549. DOI: 10.3109/00016357.2014.939709.

23. Onyeaso CO, Aderinokun GA, Arowojolu MO. The pattern of malocclusion among orthodontic patients seen in dental centre, University College Hospital, Ibadan, Nigeria. Afr J Med Med Sci 2002;31(3):207-211.

24. Sayin MO, Turkkahraman $\mathrm{H}$. Malocclusion and crowding in an orthodontically referred Turkish population. Angle's Orthod 2003;74:635-639.

25. Borzabadi-Farahani A, Borzabadi-Farahani A, Eslamipour F. Malocclusion and occlusal traits in an urban Iranian population. An epidemiological study of 11- to 14-year-old children. Eur J Orthod 2009;31(5):477-484. DOI: 10.1093/ejo/cjp031.

26. Elham SJ, Abu Alhaija ES, Al-Khateeb SN, et al. Prevalence of malocclusion in 13-15 year-old north Jordanian school children. Community Dent Health 2005;22:266-271.

27. Alhammadi MS, Halboub E, Fayed MS, et al. Global distribution of malocclusion traits: a systematic review. Dental Press J Orthod 2019;24(3):113. DOI: 10.1590/2177-6709.24.3.113.err.

28. Baeshen $\mathrm{H}$. The prevalence of major types of occlusal anomalies among Saudi middle school students. J Contemp Dent Pract 2017;18(2):142-146. DOI: 10.5005/jp-journals-10024-2005.

29. Albakri FM, Ingle N, Assery MK. Prevalence of malocclusion among male school children in Riyadh city. Open Access Maced J Med Sci 2018;6(7):1296. DOI: 10.3889/oamjms.2018.207. 